\title{
Effects of case definition and assessment frequency on lameness incidence estimates
}

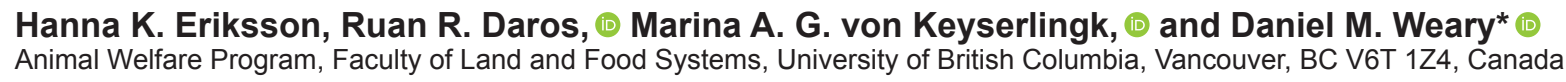

\begin{abstract}
The reliability of locomotion scoring is often low, making it unclear how a single gait score should be interpreted. In addition, differences in assessment frequency between longitudinal studies makes it hard to compare results. Our aims were to evaluate how lameness definition and assessment frequency affect measures of lameness incidence. Six dairy farms in British Columbia, Canada, were enrolled, and 262 cows that were sound at dry-off had their locomotion score (LS) assessed weekly from dry-off to calving, using a 1 to 5 scale. Cows were categorized as remaining sound or becoming lame using 3 different case definitions (LAME1: $\geq$ LS3 at least once; LAME2: $\geq 2$ consecutive scores of LS3, or $\geq$ LS4 at least once; and LAME3: $\geq 3$ consecutive scores of LS3, or $\geq$ LS4 at least once). We analyzed the correspondence between the 3 definitions with percent agreement and weighted $\kappa$ (linear and quadratic weighting). Comparing LAME1 to LAME3 resulted in lower percent agreement (53\%) and $\kappa$ values (linear $\kappa_{\mathrm{w}}$ $=0.50 ;$ quadratic $\left.\kappa_{\mathrm{w}}=0.64\right)$ than comparing LAME2 and LAME3 (85\%; linear $\kappa_{\mathrm{w}}=0.83$; quadratic $\kappa_{\mathrm{w}}=$ 0.89), indicating that cows scored LS3 twice were likely to be scored LS3 a third time. We also compared the 3 case definitions against trim records from trimmings occurring $90 \mathrm{~d}$ or less before calving $(\mathrm{n}=117)$, and used logistic regression models to determine sensitivity, specificity, and positive and negative predictive value. Using the LAME1 criterion resulted in high sensitivity (horn lesions $=0.90$; infectious lesions $=0.92$ ) and low specificity (horn $=0.21$; infectious $=0.24$ ). We observed higher specificity for LAME2 (horn $=0.62$; infectious $=$ 0.66 ) and LAME3 (horn $=0.71$; infectious $=0.77$ ), but LAME2 had higher sensitivity than LAME3 (horn = 0.89 vs. 0.64 ; infectious $=0.69$ vs. 0.64 ). When evaluating the effects of assessment frequency, we obtained 3 data sets by keeping every, every other, and every third locomotion assessment, and using LAME2 as a
\end{abstract}

Received February 4, 2019.

Accepted September 5, 2019.

*Corresponding author: dan.weary@ubc.ca case definition. More cows were categorized as lame when assessment frequency increased. Of the cows that were classified as lame when assessed weekly, $72 \%$ of the mildly lame, and $33 \%$ of the severely lame were classified as sound when assessed every third week. Our results suggest that a single LS3 score should not be used as a criterion for lameness in longitudinal studies. To correctly identify new cases of lameness, dairy cows should be assessed at least every 2 wk.

Key words: disease frequency, gait scoring, hoof pathology, lameness duration

\section{INTRODUCTION}

Lameness is one of the greatest welfare challenges for dairy cows, and many cases are associated with claw lesions (Archer et al., 2010). Despite decades of research, lameness remains a common disorder (Bicalho and Oikonomou, 2013), perhaps in part due to the difficulty in correctly identifying lame animals. Intra- and inter-observer reliability estimates often indicate low to moderate consistency when assessing locomotion (reviewed by Schlageter-Tello et al., 2014b), and it is particularly difficult to differentiate between imperfect gait and mild lameness (Schlageter-Tello et al., 2014a). This observer inconsistency introduces uncertainty into measures of prevalence and incidence.

Prevalence estimates (i.e., the proportion of animals lame at a specific time point) from cross-sectional studies have frequently been used to evaluate associations between potential risk factors and lameness (Faull et al., 1996; Barberg et al., 2007; Solano et al., 2015). Incorrectly classified animals (both sound and lame) increase the risk that true correlations are overlooked, and that spurious relationships are identified.

Cross-sectional studies can conclude only bidirectional associations (Dahoo et al., 2009a), so in recent years more effort has been made to evaluate the temporal associations between risk exposure and lameness using longitudinal studies (Green et al., 2014; Randall et al., 2016). However, in light of poor observer reliability, it is unclear how much weight should be given to single gait scores. To address this issue, some longitudinal studies have used a more stringent definition of lameness 
(e.g., 2 consecutive occasions scored as mildly lame, or 1 occasion scored as severely lame; Randall et al., 2015, 2018), but to our knowledge the effect of lameness definition on the diagnosis of new lameness cases has not been systematically evaluated. In addition, no recommendations are currently available for how often gait should be assessed to identify new cases of lameness in longitudinal studies. Assessment intervals vary considerably between lameness studies (e.g., monthly in Frankena et al., 2009; weekly in Randall et al., 2018), making it difficult to compare results.

Using data from dry cows on commercial farms, we aimed to evaluate how lameness definition and assessment frequency affect the identification and classification (mild or severe lameness) of new lameness cases. We predicted that more animals would be categorized as lame when using a less stringent lameness definition and when they were assessed more frequently, resulting in higher incidence estimates. Claw lesions have been imperfectly associated with lameness (Flower and Weary, 2006; Chapinal et al., 2009), and lameness is commonly used to identify cows in need of treatment (Whay, 2002). As such, we also compared the evaluated lameness definitions against trim records from trimmings that occurred $90 \mathrm{~d}$ or less before calving.

\section{MATERIALS AND METHODS}

\section{Farm Selection and Description}

This investigation used data from a study evaluating how lameness during the dry period affected the risk of transition-period diseases (Daros et al., 2020), approved by the Animal Care Committee at the University of British Columbia (protocol A15-0084). In brief, a convenience sample of 6 commercial dairy farms in the lower Fraser Valley region (BC, Canada) was visited weekly between May and December 2017. Farms were recruited by partnering with a local claw trimming company (AR-PE Hoof Trimming Ltd., Abbotsford, BC, Canada). Enrolled farms housed adult animals predominantly in free-stall pens ( 3 farms used deep-bedded open packs for a short time at the end of the dry period), kept dry animals separate from lactating animals, and had 153 to 543 lactating cows at the beginning of the study. Five farms kept only 1 breed (Holstein), and 1 farm kept a mix of breeds (Holstein/ Jersey/Ayrshire).

\section{Enrolled Animals}

To evaluate how case definition and assessment frequency affect measures of lameness incidence, we used only data from the 271 parous pregnant animals that were sound at first assessment and kept on-site for the whole dry period. Therefore, the study population was not a representative sample of loose-housed dairy cows, and our results should be interpreted in the context of the study objectives. Each animal was enrolled 9 wk before its estimated calving date. Because of early calving, 33 cows (mean \pm standard deviation $=12.6 \%$ $\pm 2.7 \%$ of animals per farm) were first assessed $8 \mathrm{wk}$ before their actual calving date. Because later enrollment would have provided insufficient locomotion data, we excluded 9 animals that had their first assessment $<8$ wk prepartum, leaving 262 cows in the data set. A median of 49 animals (range 9 to 73 ) was followed per farm.

\section{Locomotion Assessment}

Before data collection started, 2 observers with previous experience in conducting gait assessments were trained to provide consistent locomotion scores $(\mathbf{L S})$ using an ordinal scale of 1 to 5 (LS1 to LS2 = freely able to move; LS3 = compromised locomotion; LS4 to LS5 = severely restricted ability to move; Flower and Weary, 2006). Initial training in identification of abnormal gait characteristics (head-bob, back arch, shortened track-up, asymmetrical weight bearing, and limp), and overall locomotion scoring was conducted using video recordings of cows walking in a straight line on dry concrete. The initial training was followed by training in live observation, as used in the current study at the University of British Columbia Dairy Education and Research Centre. We evaluated inter-observer reliability after each step of the training protocol (Appendix Tables A1 and A3). Evaluating many animals might exhaust observers and negatively affect assessment accuracy (Schlageter-Tello et al., 2015), so we controlled for the number of animals used for the live reliability assessment.

Inter-observer reliability for ordinal gait assessment was evaluated using weighted $\kappa$ (Cohen, 1968) with linear and quadratic weighting (Vanbelle, 2016). Using the framework of Landis and Koch (1977), the $\kappa$ values indicated substantial to almost perfect agreement [linear weighting $\kappa_{\mathrm{w}}=0.76,95 \%$ confidence interval (CI) $0.53-0.99$; quadratic weighting $\kappa_{\mathrm{w}}=0.84,95 \%$ CI 0.69-1.00) for video assessments, and moderate agreement (linear $\kappa_{\mathrm{w}}=0.52,95 \%$ CI 0.24-0.80; quadratic $\kappa_{\mathrm{w}}$ $=0.57,95 \%$ CI $0.28-0.87)$ when evaluating live scoring reliability.

To evaluate the effects of prevalence and observer bias on the reliability measures, we dichotomized locomotion data as sound $(<\mathrm{LS} 3)$ or clinically lame $(\geq \mathrm{LS} 3$; Appendix Tables A2 and A4), and calculated the prevalence and bias indexes for video and live training 
as described by Byrt et al. (1993). Both indexes can take values between -1 and 1 ; a prevalence index of 0 indicates that equal numbers of animals were classified as sound and lame, and a bias index of 0 indicates that no systematic bias existed between observers. For video assessment, the prevalence index was 0.1 and the bias index was 0 ; for live evaluation, the prevalence index was 0.3 and the bias index was -0.1 .

We reassessed reliability for live scoring after data collection was completed (linear $\kappa_{\mathrm{w}}=0.49,95 \%$ CI 0.19-0.80; quadratic $\kappa_{\mathrm{w}}=0.55,95 \%$ CI 0.23-0.87; Appendix Table A5), and found prevalence and bias index values of 0.2 and 0 , respectively (Appendix Table A6). The similar results before and after the study period indicate that the observers maintained reliability and did not develop systematic bias over the study period.

During the study, locomotion was scored weekly during pen walks, when unrestricted animals walked on concrete while being observed directly and obliquely from behind by one of the observers. Farmers were told about animals with a score $\geq \mathrm{LS} 3$, but treatment was initiated at the discretion of the farm manager.

\section{Claw Lesion Recording}

Farms were visited every 2 to 10 wk by the same trimming company used to recruit the farms. The cows were trimmed by 1 of 3 professional trimmers, who also recorded claw lesions in accordance with the Alberta Dairy Hoof Health Project's Lesion Severity Scoring Guide (www.hoofhealth.ca/Section5/ LesionSeverityGuide_v0.5.pdf), using Hoof Supervisor System software (KS Dairy Consulting, Inc., Dresser, WI). On 5 of the enrolled farms, the animals were routinely trimmed before dry-off, and on the sixth farm animals were selected for trimming based on toe length. After the on-farm data collection was completed, we downloaded records for trimmings that occurred in 2017 and extracted lesion records from trimmings that occurred $90 \mathrm{~d}$ or less before calving, including during the dry period. Of 262 enrolled cows, only 117 had trimming data within this period. Each animal was classified as having or not having noninfectious [sole hemorrhage $(\mathrm{n}=1)$, sole ulcer $(\mathrm{n}=3)$, white line lesion $(\mathrm{n}=4)$, toe ulcer $(\mathrm{n}=2) ; 1$ animal had $>1$ type of claw horn lesion] and infectious claw lesions [digital dermatitis $(\mathrm{n}=22)$, interdigital dermatitis $(\mathrm{n}=6) ; 2$ animals had both types of infectious lesions].

\section{Data Handling and Statistical Analyses}

Lameness Definition. To evaluate the effects of case definition on the identification of new lameness cases, clinical lameness was defined as follows: (1) scored LS3 or higher on at least 1 occasion (LAME1); (2) scored LS3 on at least 2 consecutive occasions or scored LS4 or higher at least once (LAME2); or (3) scored LS3 on at least 3 consecutive occasions or scored LS4 or higher at least once (LAME3). We justified the use of 1 score of $\geq$ LS4 by the relative ease of identifying animals with severely restricted ability to move (Schlageter-Tello et al., 2014a), making it unlikely that sound animals would be scored LS4 or higher. We treated LAME3 as the gold standard for clinical lameness and used $\geq$ LS4 to define severe lameness (Flower and Weary, 2006).

Assessment Frequency. When evaluating the effects of assessment frequency, we retained the results of every assessment (ASSM1), every other assessment (ASSM2), or every third assessment (ASSM3) for each animal; the first assessment was the same for all 3 data sets. For cows that were gait scored for the first time 9 wk before calving ( $87 \%$ of enrolled animals), 4 observations remained in ASSM3; animals first observed 8 wk prepartum (13\%) were scored 3 times. After creating the 3 data sets, we used the case definition found to have the best test characteristics to categorize cows as sound or lame, treating ASSM1 as the gold standard.

Statistical Analyses. All data analyses were performed in R 3.4.4 (RStudio Team, 2016; Wickham et al., 2017; R Core Team, 2018; Wickham and Henry, 2018). Graphing was performed using the ggplot2 package (Wickham, 2009). Mixed logistic regression models with farm as random intercept were fitted with maximum likelihood using the lme4 package (Bates et al., 2015) to estimate sensitivity (proportion of true positives that were correctly identified by the test), specificity (proportion of true negatives correctly identified by the test), positive predictive value (PPV; probability of correct positive test), and negative predictive value (NPV; probability of correct negative test) as described by Coughlin et al. (1992) to evaluate the effect of assessment frequency. We evaluated the uncertainty of the estimates with exact binomial $95 \%$ confidence intervals (Dahoo et al., 2009b). We calculated percent agreement from contingency tables. Because the 3 lameness criteria were nested, it was not possible to estimate their relative test attributes with logistic regression due to complete data separation; as such, we split the data per farm when evaluating correspondence between the 3 case definitions, and we calculated sensitivity, specificity, PPV, NPV, and percent agreement from contingency tables per farm. However, we used mixed logistic regression models when comparing the different lameness criteria against recorded claw lesions.

We evaluated reliability in the classification of lameness severity (sound, mildly lame, severely lame) depending on lameness definition and assessment fre- 
quency using weighted $\kappa$ (linear and quadratic weighting; Vanbelle, 2016) and the irr (Gamer et al., 2012) and rel (Lo Martire, 2017) packages. The $\kappa$ statistic assumes that the data are independent, which has generally been interpreted as observers having no knowledge of previous assessments (Sim and Wright, 2005), and that repeated assessments of the same subject must be accounted for (Haley and Osberg, 1989). To evaluate whether dependencies in our data affected the reliability estimates, we obtained $\kappa$ values first for all animals, and then separately for the 3 largest herds $(\mathrm{n}=50-73)$.

Because lameness incidence was calculated from a closed population, we used incidence proportion as the outcome (number of cows becoming lame/total number of cows; Dahoo et al., 2009b). We tested differences in farm incidence depending on lameness definition and assessment frequency using Wilcoxon signed rank tests. The low number of enrolled animals in 1 of the farms $(\mathrm{n}=9)$ increased uncertainty in the incidence estimate for this farm; therefore, we ran all analyses with and without animals from this farm. Excluding the data from this farm caused no substantial differences in the results, so analyses using the full data set are presented here. The data sets and accompanying $\mathrm{R}$ script are available at https://doi.org/10.5683/SP2/9XRRSJ.

\section{RESULTS AND DISCUSSION}

\section{Locomotion Assessment}

The high weighted $\kappa$ values after video training suggested that the observers could differentiate between gait scores. The lower values for the linear-weighted $\kappa$ statistic compared with the quadratic-weighted $\kappa$ statistic indicate that disagreements generally consisted of 1 LS unit (Vanbelle, 2016). The consistently low bias index values suggested that the lower weighted $\kappa$ values for live scoring were not owing to systematic differences in how the observers scored locomotion, but rather that it was difficult to differentiate between LS2 and LS3 (Appendix Table A4 and Table A6; Vach, 2005). This finding aligned with that of Schlageter-Tello et al. (2015), who reported the lowest intra-observer percent agreement for LS2 and LS3 scores. Taken together, these results emphasize that the interpretation of longitudinal locomotion data should account for observer inconsistency.

On 10 occasions, locomotion assessment could not be performed ( $0.4 \%$ of all occasions); on 8 occasions, the cows were calving during the visit and on 2 occasions, the cows were not found in their home pens. No animal lacked more than 1 locomotion score. The percentages of LS1, LS2, LS3, LS4, and LS5 were 0, 69.5, $26.5,4$, and $0 \%$, respectively; 18,60 , and $22 \%$ of the animals had a maximum score of LS2, LS3, and LS4, respectively. The reason that no animal was scored as having a perfect gait may have been that the home pens did not provide optimal conditions for walking freely (other animals present, manure-contaminated concrete; Telezhenko et al., 2017). It was common for locomotion scores to change from one visit to the next; approximately one-third of the scores changed between consecutive assessments. In agreement with Reader et al. (2011), scores were much more likely to change by a single unit (e.g., from LS2 to LS3, or LS3 to LS4; $94 \%$ of all changes) than by a score of 2 or more (e.g., from LS2 to LS4). Some of these changes could be explained by inconsistency within and between observers (Figure $1 \mathrm{~A}$ and $\mathrm{C}$ ), as well as by animals transitioning between soundness and lameness, and vice versa (Figure 1D and $\mathrm{E})$.

\section{Effect of Lameness Definition}

The number of cows categorized as becoming lame differed depending on the definition used [LAME1 $\mathrm{n}$ $=215$ ( $82 \%$ of enrolled animals); LAME2 $\mathrm{n}=131$ (50\%); LAME3 $\mathrm{n}=93(35 \%)]$. We attributed these differences to animals being considered sound when using the LAME3 criteria $(\mathrm{n}=169)$, while being classified as lame when LAME1 (122 of 169 animals) or LAME2 (38 of 169 animals) criteria were used. The high proportion of animals categorized as lame when using LAME1 suggests that the lameness incidence was overestimated, especially considering that 44 of the 158 lame (28\%) LAME1 animals received a score of LS3 on only 1 occasion.

The higher specificity, PPV, and percent agreement (Table 1) found when comparing LAME2 and LAME3 suggests that animals scored $\geq \mathrm{LS} 3$ on 2 consecutive occasions were likely to be scored $\geq \mathrm{LS} 3$ a third time. This finding was also reflected by weighted $\kappa$ values indicating almost perfect agreement (linear weighting $\kappa_{\mathrm{w}}=0.83,95 \%$ CI $0.77-0.88$; quadratic weighting $\kappa_{\mathrm{w}}=$ 0.89; 95\% CI 0.85-0.93) between LAME2 and LAME3, versus only moderate to substantial agreement (linear $\kappa_{\mathrm{w}}=0.50,95 \%$ CI $0.43-0.57$; quadratic $\kappa_{\mathrm{w}}=0.64,95 \%$ CI 0.58-0.70) between LAME1 and LAME3. We found the same patterns when evaluating reliability measures separately for the 3 largest farms, with better agreement between LAME2 and LAME3 (linear $\kappa_{\mathrm{w}}=0.77$ 0.87; quadratic $\left.\kappa_{\mathrm{w}}=0.84-0.92\right)$, than when comparing LAME1 to LAME3 (linear $\kappa_{\mathrm{w}}=0.36-0.61$; quadratic: $\left.\kappa_{\mathrm{w}}=0.47-0.73\right)$ for all 3 farms. Farm incidence measures were higher when using LAME1 (average farm incidence $=81 \% ; \mathrm{Z}=21 ; P=0.03$ ) and LAME2 (average farm incidence $=48 \% ; \mathrm{Z}=15 ; P=0.06)$, compared with LAME3 (average farm incidence $=35 \%$ ). 
Table 1. Sensitivity, specificity, and positive and negative predictive value (PPV and NPV) for the identification of animals with claw lesions depending on lameness criteria and assessment frequency ${ }^{1}$

\begin{tabular}{|c|c|c|c|c|c|}
\hline Item & $\begin{array}{l}\text { Sensitivity } \\
(95 \% \text { CI })^{2}\end{array}$ & $\begin{array}{l}\text { Specificity } \\
(95 \% \text { CI })^{2}\end{array}$ & $\begin{array}{c}\text { PPV } \\
(95 \% \text { CI })^{2}\end{array}$ & $\begin{array}{c}\text { NPV } \\
(95 \% \mathrm{CI})^{2}\end{array}$ & $\begin{array}{c}\text { Agreement, } \\
\%\end{array}$ \\
\hline \multicolumn{6}{|c|}{$\overline{\text { Lameness criteria }(\mathrm{n}=262)^{3}}$} \\
\hline LAME1 & - & $0.13-0.40^{4}$ & $0.24-0.57^{4}$ & - & $43-67$ \\
\hline \multicolumn{6}{|c|}{ Assessment frequency $(\mathrm{n}=262)$} \\
\hline ASSM2 & $0.68(0.62-0.74)$ & $0.95(0.92-0.97)$ & $0.93(0.89-0.96)$ & $0.75(0.69-0.80)$ & 81 \\
\hline ASSM3 & $0.44(0.39-0.51)$ & $0.98(0.95-0.99)$ & $0.95(0.92-0.97)$ & $0.64(0.58-0.70)$ & 71 \\
\hline
\end{tabular}

${ }^{1}$ LAME $1=\geq$ LS3 on $\geq 1$ occasion; LAME $2=$ LS3 on $\geq 2$ consecutive occasions or $\geq$ LS4 on $\geq 1$ occasion; LAME3 $=$ LS3 on $\geq 3$ consecutive occasions or $\geq$ LS4 on $\geq 1$ occasion; ASSM1 = weekly gait assessments; ASSM2 = gait assessments every 2 wk; ASSM3 = gait assessments every 3 wk. Because the nested lameness criteria led to complete data separation when analyzed using mixed logistic regression, values for lameness criteria were obtained per farm $(\mathrm{n}=6)$ from contingency tables. We used mixed logistic regression models (farm included as random intercept) to estimate values for assessment frequency. We used LAME3 as the gold standard for lameness, and compared it against LAME1 and LAME2. We used ASSM1 as the gold standard for assessment frequency, and compared it against ASSM2 and ASSM3; for all assessment intervals, we used LAME2 as the lameness criteria. Percent agreement was calculated from contingency tables. Lameness scores were as follows: LS1 to LS2 = freely able to move; LS3 = compromised locomotion; LS4 to LS5 = severely restricted ability to move. LS = locomotion score.

${ }^{2}$ Exact binomial confidence intervals.

${ }^{3}$ Because of nested lameness criteria, sensitivity and NPV values had to equal 1.00. Because these values were an effect of our definitions rather than true test characteristics, the values are not shown.

${ }^{4}$ The range represents the lowest and highest values for the farms.

Our findings demonstrate that assigning equal weight to occasional and sequential LS3 scores introduces noise when identifying new cases of lameness (Figure 1A). It is possible that if we had performed locomotion scoring in more controlled conditions (i.e., not on commercial farms), the number of false positives would have been lower. Although we did not systematically assess movement when transitioning from lying to standing, we ob- served that heavy animals in late gestation were often visibly stiff directly after rising; this may have resulted in a higher rate of misclassification of lameness for the cows used in this study.

The low agreement between LAME1 and LAME3 suggests that lameness prevalence estimates contain uncertainty and should be viewed with caution. It is possible that the reported divergence in estimates of

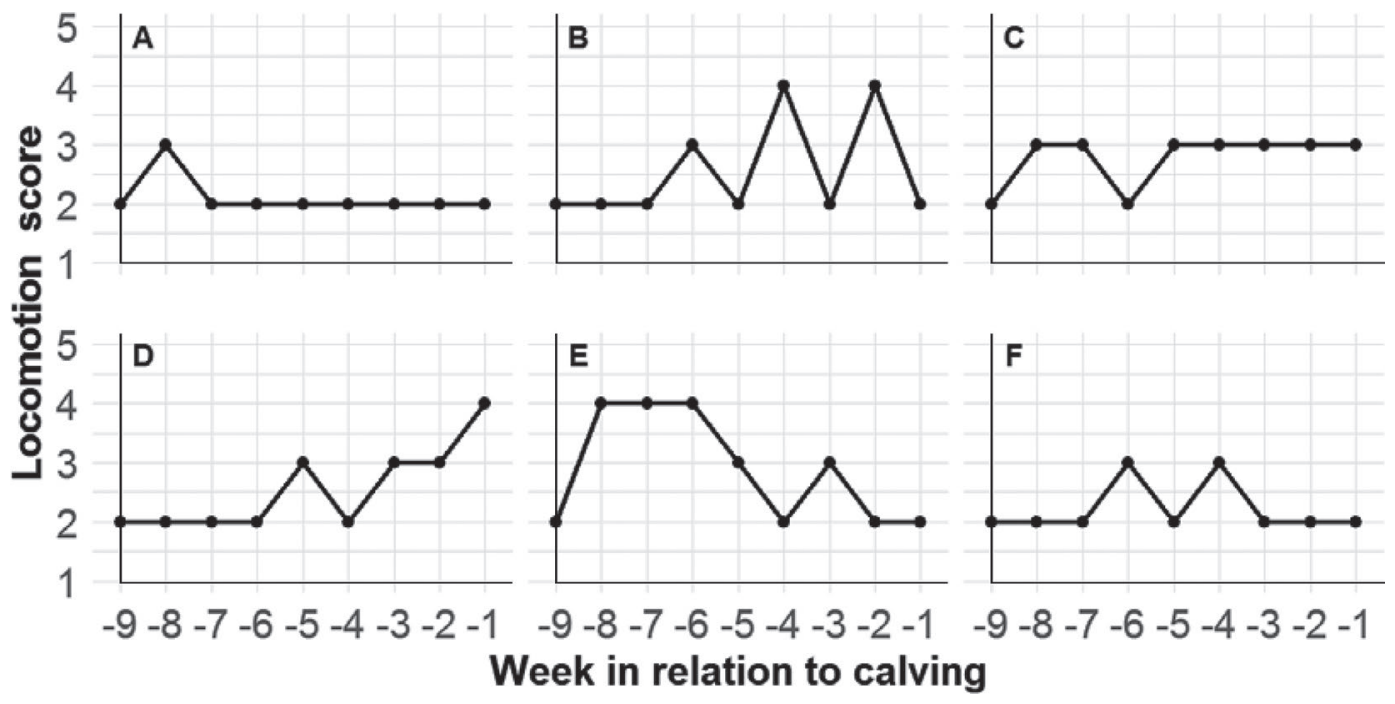

Figure 1. Weekly locomotion scores (LS) for 6 different animals. The points illustrate recorded gait scores, and the lines represent interpolations of gait change between assessments. When one $\geq$ LS3 was used to define lameness, cow A was considered a new lameness case, contributing to farm incidence. With decreasing assessment frequency, it became more difficult to identify all lame animals; cow B was categorized as sound when evaluated every 2 wk despite multiple scores of LS4, and cow C when assessed every 3 wk (mild lameness was defined as $\geq 2$ consecutive LS3 when evaluating assessment frequency). The presence of isolated LS2 scores at the beginning (D) and end (E) of severe lameness events suggests that it is difficult to distinguish between LS2 and LS3 in marginally lame animals, which raises the question of how to interpret the trajectory for cow F. Lameness scores were as follows: LS1 to LS2 = freely able to move; LS3 = compromised locomotion; LS4 to LS5 = severely restricted ability to move. 
Table 2. Sensitivity, specificity, and positive and negative predictive values (PPV and NPV) for the identification of animals with claw lesions using different lameness definitions ${ }^{1,2}$

\begin{tabular}{|c|c|c|c|c|c|}
\hline Item & $\begin{array}{l}\text { Sensitivity } \\
(95 \% \mathrm{CI})^{3}\end{array}$ & $\begin{array}{l}\text { Specificity } \\
(95 \% \text { CI })^{3}\end{array}$ & $\begin{array}{c}\text { PPV } \\
(95 \% \mathrm{CI})^{3}\end{array}$ & $\begin{array}{c}\text { NPV } \\
(95 \% \mathrm{CI})^{3}\end{array}$ & $\underset{\%}{\text { Agreement, }}$ \\
\hline \multicolumn{6}{|c|}{ Noninfectious lesions $(\mathrm{n}=9 \text { of } 117 \text { trimmed cows })^{4}$} \\
\hline LAME3 & $0.64(0.55-0.73)$ & $0.71(0.62-0.79)$ & $0.16(0.09-0.23)$ & $0.96(0.91-0.99)$ & 70 \\
\hline \multicolumn{6}{|c|}{ Infectious lesions $(\mathrm{n}=27 \text { of } 117 \text { trimmed cows })^{5}$} \\
\hline LAME1 & $0.92(0.86-0.96)$ & $0.24(0.17-0.33)$ & $0.05(0.02-0.11)$ & $0.98(0.95-1.00)$ & 39 \\
\hline
\end{tabular}

${ }^{1}$ LAME1 $=\geq$ LS3 on $\geq 1$ occasion; LAME2 $=$ LS3 on $\geq 2$ consecutive occasions or $\geq$ LS4 on $\geq 1$ occasion; LAME3 = LS3 on $\geq 3$ consecutive occasions or $\geq$ LS4 on $\geq 1$ occasion. Lameness scores were as follows: LS1 to LS2 = freely able to move; LS3 = compromised locomotion; LS4 to LS5 $=$ severely restricted ability to move. LS $=$ locomotion score.

${ }^{2}$ Estimated using mixed logistic regression models (farm included as random intercept). Percent agreement was calculated from contingency tables. Separate tests were performed for noninfectious and infectious claw lesions.

${ }^{3}$ Exact binomial confidence intervals.

${ }^{4}$ Sole hemorrhage, sole ulcer, white line lesion, and toe ulcers.

${ }^{5}$ Digital dermatitis and interdigital dermatitis.

lameness prevalence between farmers and trained assessors (e.g., Espejo et al., 2006; Leach et al., 2010) is not because assessors are more skilled in identifying mildly lame animals (e.g., Alawneh et al., 2012), but because farmers base their evaluations on multiple observations. In a qualitative study, Horseman et al. (2014) reported that many of the enrolled farmers $(\mathrm{n}=12)$ were able to detect mild lameness, but referred to this as impaired mobility. Leach et al. (2012) reported that some lameness cases seem to self-cure, which may explain why farmers consider only LS4 and LS5 as "true" lameness.

Although we used LAME3 as the gold standard in our analyses, the duration of some true lameness cases might have been too short to be correctly identified under the conditions of this study (weekly gait assessments). Given the high agreement and reliability between LAME2 and LAME3, we suggest that 2 consecutive LS3 scores is a reasonable cutoff for new cases of mild lameness in longitudinal research.

\section{Relation Between Lameness Definition and Claw Lesions}

Table 2 shows the percentage agreement, sensitivity, specificity, PPV, and NPV when using LAME1, LAME2, and LAME3 to identify animals with noninfectious and infectious claw lesions. The high sensitivity we found for LAME1 suggests that most animals with claw lesions had at least a brief period of altered gait during the dry period. However, the low specificity and PPV indicate that short-term gait impairment was also observed in many of the animals that did not have claw lesions at trimming, suggesting that the LAME1 criterion may introduce bias in the evaluation of longitudinal locomotion data.
When we used LAME2 and LAME3 definitions, the number of false positives decreased, leading to higher specificity and percent agreement for both noninfectious and infectious lesions (Table 2). When comparing LAME2 and LAME3, LAME2 had higher sensitivity (noninfectious 0.89 vs. 0.64 ; infectious 0.69 vs. 0.64 ), and lower specificity (noninfectious 0.62 vs. 0.71 ; infectious 0.66 vs. 0.77). However, we also obtained low PPV when LAME2 and LAME3 were used as lameness criteria, possibly because painful lesions at the level of the corium were not visible on the sole surface at the time of trimming. All case definitions had high NPV, indicating that cows that never had a gait score $\geq$ LS3 were unlikely to have lesions at trimming.

\section{Effects of Assessment Frequency}

We used the LAME2 criteria when evaluating the effect of assessment frequency. Fewer animals were categorized as becoming lame when assessment frequency decreased [ASSM1 $\mathrm{n}=131$ (50\% of enrolled animals); ASSM2 $\mathrm{n}=96(37 \%)$; ASSM3 $\mathrm{n}=62(24 \%)]$. The increasing difficulty in correctly identifying new lameness cases when assessment occurred less frequently was reflected in the higher sensitivity and NPV for ASSM2 compared with ASSM3 when evaluated against weekly assessments (Table 1).

The weighted $\kappa$ values showed substantial agreement between ASSM1 and ASSM2 (linear $\kappa_{\mathrm{w}}=0.68,95 \%$ CI $0.60-0.76$; quadratic $\kappa_{\mathrm{w}}=0.75,95 \%$ CI $\left.0.67-0.82\right)$, and moderate agreement between ASSM1 and ASSM3 (linear $\kappa_{\mathrm{w}}=0.48,95 \%$ CI $0.39-0.57$; quadratic $\kappa_{\mathrm{w}}=$ $0.55,95 \%$ CI $0.45-0.65$; Landis and Koch, 1977). Similar results were obtained when evaluating reliability measures for the 3 largest farms, with higher agreement 
between weekly and fortnightly assessments (linear $\kappa_{\mathrm{w}}$ $=0.63-0.78 ;$ quadratic $\left.\kappa_{\mathrm{w}}=0.73-0.85\right)$, than when comparing weekly assessments with assessments every 3 wk (linear $\kappa_{\mathrm{w}}=0.12-0.60$; quadratic $\kappa_{\mathrm{w}}=0.12-0.68$ ). A large percentage of animals categorized as lame when assessed weekly was classified as sound when assessed every other week ( $47 \%$ of mildly lame and $12 \%$ of severely lame animals), and every third week ( $72 \%$ of mildly lame and $33 \%$ of severely lame animals). Approximately $20 \%$ of the animals categorized as severely lame when assessed weekly were classified as mildly lame when assessed less frequently. Farm incidence estimates were higher when animals were scored every week (average farm incidence $=48 \%$ ), compared with every other week (average farm incidence $=36 \%$; Z $=15 ; P=0.06$ ), and every third week (average farm incidence $=25 \% ; \mathrm{Z}=15 ; P=0.06)$.

\section{Lameness Duration}

To explore why lameness classification differed between ASSM1, ASSM2, and ASSM3, we determined the number of weeks an animal was categorized as lame from ASSM1, using 2 consecutive scores of LS2 as the definition of being cured. Because the data collection ended at calving, the lameness duration for animals classified as lame on the last assessment was unknown. We found that $12 \%$ of the animals categorized as lame for $\leq 2$ visits were lame when censored; the corresponding value for animals lame for $\geq 4$ visits was $78 \%$. Of the animals that changed category from lame to sound when assessed less frequently, 69\% (ASSM2) and 42\% (ASSM3) were lame for $\leq 2 \mathrm{wk}$, and $21 \%$ (ASSM2) and $49 \%$ (ASSM3) were lame for $\geq 4 \mathrm{wk}$.

Figure 2 shows a histogram of the number of weeks classified as lame for mildly and severely lame animals. The markedly bimodal distribution of lameness duration for mildly lame animals suggests that several animals were incorrectly classified as lame when assessed weekly, or that this distribution represents 2 populations of animals with different underlying causes of lameness. In our study, 35\% of the animals with infectious claw lesions (9 of 26 animals) were scored $\geq \mathrm{LS} 3$ for $\leq 1 \mathrm{wk}$, but the same was true for just $11 \%$ of the animals with noninfectious claw lesions (1 of 9 animals). Because lame cows were reported to farmers after every visit, it is possible that treatment was initiated shortly after the onset of lameness, at least on some farms. Early treatment may have shortened the duration of readily treatable lameness cases, resulting in the bimodal distribution of lameness duration. Consistent with this idea, Whay et al. (1998) reported that animals lame because of interdigital phlegmon or

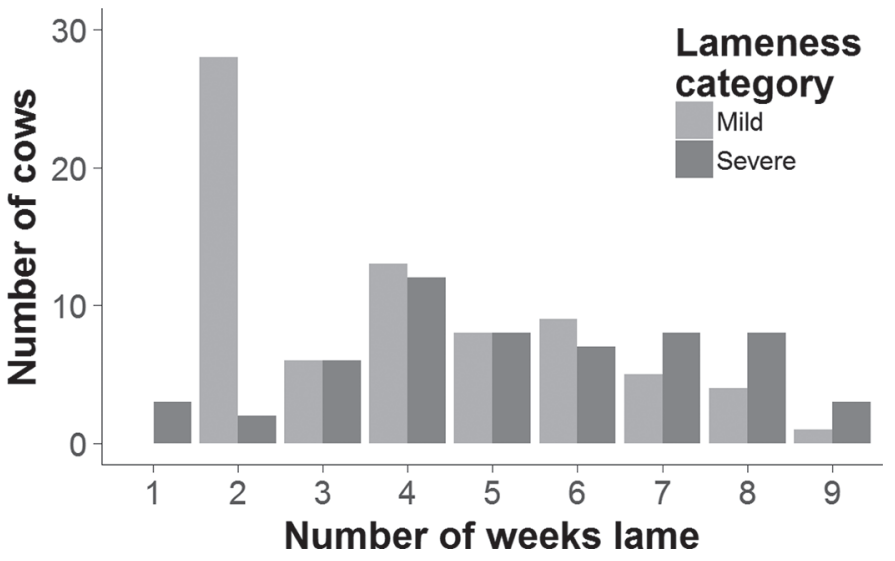

Figure 2. Number of weeks that cows were lame during the dry period, for mildly and severely lame cows. Mild lameness was defined as a locomotion score (LS) of LS3 for $\geq 2$ consecutive weeks, and severe lameness was defined as at least 1 score of $\geq$ LS4. Lameness scores were as follows: LS1 to LS2 $=$ freely able to move; LS3 = compromised locomotion; LS4 to LS5 = severely restricted ability to move.

digital dermatitis were all sound $28 \mathrm{~d}$ after treatment, but lame animals treated for sole ulcers, white line disease, or heel erosion still had an impaired gait. Multiple studies have reported that previous lameness events increase the risk of future lameness (e.g., Rowlands et al., 1986; Green et al., 2014; Randall et al., 2018), but so far the effect of previous lameness duration has not been evaluated. Before this relationship is assessed, it would be premature to conclude that short lameness events are inconsequential for animals.

In the current study, lame cows often changed locomotion scores between assessments. For example, $89 \%$ of severely lame cows were scored LS3 at least once during the lameness event, and $22 \%$ of mildly lame and $28 \%$ of severely lame cows were occasionally scored LS2. These fluctuations resulted in some animals changing category from lame to sound when assessed less frequently (ASSM2 19\% of all misclassified animals; ASSM3 18\%; see Figure 1 for examples). The number of animals presenting the locomotion patterns illustrated in Figure 1 are provided in Table 3.

Based on the large number of cows identified as lame for $\geq 4$ wk that were misclassified as sound when assessed every third week, we suggest that locomotion should be evaluated at least fortnightly when conducting longitudinal research. If lameness events of short duration are of interest, assessment should occur even more frequently.

Because the cows in our study were followed only during the dry period, our findings may not be generalizable to other parts of the lactation cycle. However, Reader et al. (2011) reported that lactating cows frequently changed locomotion scores between fortnightly 
Tetra-Laval through the Sweden-America Foundation (Stockholm, Sweden), and RRD was supported by the Science Without Borders Program (CNPq - National Council for Scientific and Technological Development, Brazil). Funding for this project has been provided by the British Columbia Dairy Association through the Dairy Industry Research and Education Committee, and the Agriculture and Agri-Food Canada and the British Columbia Ministry of Agriculture through the Canada-British Columbia Agri-Innovation Program under Growing Forward 2, a federal-provincial-territorial initiative. The program is delivered by the Investment Agriculture Foundation of British Columbia. Opinions expressed in this document are those of the author and not necessarily those of the Governments of Canada and British Columbia or the Investment Agriculture Foundation of British Columbia. The Governments of Canada and British Columbia, and the Investment Agriculture Foundation of British Columbia, and their directors, agents, employees, or contractors will not be liable for any claims, damages, or losses of any kind whatsoever arising out of the use of, or reliance upon, this information. General funding for the Animal Welfare Program is provided by the Canada's Natural Sciences and Engineering Research Council Industrial Research Chair Program (Ottawa, ON, Canada) with contributions from Dairy Farmers of Canada (Ottawa, ON, Canada), the British Columbia Dairy Association (Burnaby, BC, Canada), Westgen Endowment Fund (Milner, BC, Canada), Intervet Canada Corporation (Kirkland, QC, Canada), Zoetis (Kirkland, QC, Canada), Novus International Inc. (Oakville, ON, Canada), the British Columbia Cattle Industry Development Fund (Kamloops, BC, Canada), Alberta Milk (Edmonton, AB, Canada), Valacta (St Anne-de-Bellevue, QC, Canada) and CanWest DHI (Guelph, ON, Canada).

\section{REFERENCES}

Alawneh, J. I., R. A. Laven, and M. A. Stevenson. 2012. Interval between detection of lameness by locomotion scoring and treatment for lameness: A survival analysis. Vet. J. 193:622-625. https://doi .org/10.1016/j.tvjl.2012.06.042.

Archer, S., N. Bell, and J. Huxley. 2010. Lameness in UK dairy cows: A review of the current status. In Pract. 32:492-504. https://doi .org/10.1136/Inp.C6672.

Barberg, A. E., M. I. Endres, J. A. Salfer, and J. K. Reneau. 2007. Performance and welfare of dairy cows in an alternative housing system in Minnesota. J. Dairy Sci. 90:1575-1583.

Bates, D., M. Maechler, B. Bolker, and S. Walker. 2015. Fitting linear mixed-effect models using lme4. J. Stat. Softw. 67:1-48. https:// doi.org/10.18637/jss.v067.i01.

Bicalho, R. C., and G. Oikonomou. 2013. Control and prevention of lameness associated with claw lesions in dairy cows. Livest. Sci. 156:96-105. https://doi.org/10.1016/j.livsci.2013.06.007.

Byrt, T., J. Bishop, and J. B. Carlin. 1993. Bias, prevalence and kappa. J. Clin. Epidemiol. 46:423-429.
Chapinal, N., A. M. de Passillé, D. M. Weary, M. A. G. von Keyserlingk, and J. Rushen. 2009. Using gait score, walking speed, and lying behavior to detect hoof lesions in dairy cows. J. Dairy Sci. 92:4365-4374. https://doi.org/10.3168/jds.2009-2115.

Cohen, J. 1968. Nominal scale agreement with provision for scaled disagreement or partial credit. Psychol. Bull. 70:213-220. https:// doi.org/10.1037/h0026256.

Coughlin, S. S., B. Trock, M. H. Criqui, L. W. Pickle, D. Browner, and M. Tefft. 1992. The logistic modeling of sensitivity, specificity, and predictive value of a diagnostic test. J. Clin. Epidemiol. 45:1-7.

Dahoo, I., W. Martin, and H. Stryhn. 2009a. Introduction to observational studies. Pages 152-166 in Veterinary Epidemiological Research. 2nd ed. VER Inc., Charlotte, NC.

Dahoo, I., W. Martin, and H. Stryhn. 2009b. Measures of disease frequency. Pages 73-90 in Veterinary Epidemiological Research. 2nd ed. VER Inc., Charlotte, NC.

Daros, R. R., H. K. Eriksson, D. M. Weary, and M. A. G. von Keyserlingk. 2020. The relationship between transition period diseases and lameness, feeding time, and body condition during the dry period. J. Dairy Sci. 103:649-665. https://doi.org/10.3168/jds.2019 -16975 .

Espejo, L. A., M. I. Endres, and J. A. Salfer. 2006. Prevalence of lameness in high-producing Holstein cows housed in freestall barns in Minnesota. J. Dairy Sci. 89:3052-3058. https://doi.org/10.3168/ jds.S0022-0302(06)72579-6.

Faull, W. B., J. W. Hughes, M. J. Clarkson, D. Y. Downham, F. J. Manson, J. B. Merritt, R. D. Murray, W. B. Russell, J. E. Sutherst, and W. R. Ward. 1996. Epidemiology of lameness in dairy cattle: The influence of cubicles and indoor and outdoor walking surfaces. Vet. Rec. 139:130-136. https://doi.org/10.1136/ vr.139.6.130.

Flower, F. C., and D. M. Weary. 2006. Effect of hoof pathologies on subjective assessments of dairy cow gait. J. Dairy Sci. 89:139-146. https://doi.org/10.3168/jds.S0022-0302(06)72077-X.

Frankena, K., J. G. C. J. Somers, W. G. P. Schouten, J. V. van Stek, J. H. M. Metz, E. N. Stassen, and E. A. M. Graat. 2009. The effect of digital lesions and floor type on locomotion score in Dutch dairy cows. Prev. Vet. Med. 88:150-157. https://doi.org/10.1016/ j.prevetmed.2008.08.004.

Gamer, M., J. Lemon, I. Fellows, and P. Singh. 2012. irr: Various coefficients of interrater reliability and agreement. $\mathrm{R}$ package version 0.84. https://CRAN.R-project.org/package $=$ irr.

Green, L. E., J. N. Huxley, C. Banks, and M. J. Green. 2014. Temporal associations between low body condition, lameness and milk yield in a UK dairy herd. Prev. Vet. Med. 113:63-71. https://doi.org/10 $.1016 /$ j.prevetmed.2013.10.009.

Haley, S. M., and J. S. Osberg. 1989. Kappa coefficient calculation using multiple ratings per subject: A special communication. Phys. Ther. 69:970-974. https://doi.org/10.1093/ptj/69.11.970.

Horseman, S. V., E. J. Roe, J. N. Huxley, N. J. Bell, C. S. Mason, and H. R. Whay. 2014. The use of in-depth interviews to understand the process of treating lame dairy cows from the farmers' perspective. Anim. Welf. 23:157-165. https://doi.org/10.7120/09627286 .23 .2 .157 .

Landis, J. R., and G. G. Koch. 1977. The measurement of observer agreement for categorical data. Biometrics 33:159-174.

Leach, K. A., D. A. Tisdall, N. J. Bell, D. C. J. Main, and L. E. Green. 2012. The effects of early treatment for hindlimb lameness in dairy cows on four commercial UK farms. Vet. J. 193:626-632. https:// doi.org/10.1016/j.tvjl.2012.06.043.

Leach, K. A., H. R. Whay, C. M. Maggs, Z. E. Barker, E. S. Paul, A. K. Bell, and D. C. J. Main. 2010. Working towards a reduction in cattle lameness : 1 . Understanding barriers to lameness control on dairy farms. Res. Vet. Sci. 89:311-317. https://doi.org/10.1016/j .rvsc.2010.02.014

Lo Martire, R. 2017. rel: Reliability coefficients. R package version 1.3.1. https://CRAN.R-project.org/package $=$ rel.

R Core Team. 2018. R: A language and environment for statistical computing. R Foundation for Statistical Computing, Vienna, Austria. https://www.R-project.org/. 
Randall, L. V., M. J. Green, M. G. G. Chagunda, C. Mason, S. C. Archer, L. E. Green, and J. N. Huxley. 2015. Low body condition predisposes cattle to lameness: An 8-year study of one dairy herd. J. Dairy Sci. 98:3766-3777. https://doi.org/10.3168/jds.2014-8863.

Randall, L. V., M. J. Green, M. G. G. Chagunda, C. Mason, L. E. Green, and J. N. Huxley. 2016. Lameness in dairy heifers: Impacts of hoof lesions present around first calving on future lameness, milk yield and culling risk. Prev. Vet. Med. 133:52-63. https://doi .org/10.1016/j.prevetmed.2016.09.006.

Randall, L. V., M. J. Green, L. E. Green, M. G. G. Chagunda, C. Mason, S. C. Archer, and J. N. Huxley. 2018. The contribution of previous lameness events and body condition score to the occurrence of lameness in dairy herds: A study of 2 herds. J. Dairy Sci. 101:1311-1324. https://doi.org/10.3168/jds.2017-13439.

Reader, J. D., M. J. Green, J. Kaler, S. A. Mason, and L. E. Green. 2011. Effect of mobility score on milk yield and activity in dairy cattle. J. Dairy Sci. 94:5045-5052. https://doi.org/10.3168/jds 2011-4415.

Rowlands, G. J., S. Lucey, and A. M. Russell. 1986. Susceptibility to disease in the dairy cow and its relationship with occurrences of other diseases in the current or preceding lactation. Prev. Vet. Med. 4:223-234. https://doi.org/10.1016/0167-5877(86)90025-5.

RStudio Team. 2016. RStudio: Integrated development environment for R. RStudio Inc., Boston, MA. http://www.rstudio.com/.

Schlageter-Tello, A., E. A. M. Bokkers, P. W. G. Groot Koerkamp, T. Van Hertem, S. Viazzi, C. E. B. Romanini, I. Halachmi, C. Bahr, D. Berckmans, and K. Lokhorst. 2014a. Effect of merging levels of locomotion scores for dairy cows on intra- and interrater reliability and agreement. J. Dairy Sci. 97:5533-5542. https://doi.org/10 $.3168 /$ jds.2014-8129.

Schlageter-Tello, A., E. A. M. Bokkers, P. W. G. Groot Koerkamp, T. Van Hertem, S. Viazzi, C. E. B. Romanini, I. Halachmi, C. Bahr, D. Berckmans, and K. Lokhorst. 2015. Relation between observed locomotion traits and locomotion score in dairy cows. J. Dairy Sci. 98:8623-8633. https://doi.org/10.3168/jds.2014-9059.

Schlageter-Tello, A., E. A. M. Bokkers, P. W. G. G. Koerkamp, T. Van Hertem, S. Viazzi, C. E. B. Romanini, I. Halachmi, C. Bahr, D. Berckmans, and K. Lokhorst. 2014b. Manual and automatic locomotion scoring systems in dairy cows: A review. Prev. Vet. Med. 116:12-25. https://doi.org/10.1016/j.prevetmed.2014.06.006.

Sim, J., and C. C. Wright. 2005. The kappa statistic in reliability studies: Use, interpretation, and sample size requirements. Phys. Ther. 85:257-268. https://doi.org/10.1093/ptj/85.3.257.
Solano, L., H. W. Barkema, E. A. Pajor, S. Mason, S. J. LeBlanc, J. C. Zaffino Heyerhoff, C. G. R. Nash, D. B. Haley, E. Vasseur, D. Pellerin, J. Rushen, A. M. de Passillé, and K. Orsel. 2015. Prevalence of lameness and associated risk factors in Canadian HolsteinFriesian cows housed in freestall barns. J. Dairy Sci. 98:6978-6991. https://doi.org/10.3168/jds.2015-9652.

Telezhenko, E., M. Magnusson, and C. Bergsten. 2017. Gait of dairy cows on floors with different slipperiness. J. Dairy Sci. 100:64946503. https://doi.org/10.3168/jds.2016-12208.

Vach, W. 2005. The dependence of Cohen's kappa on the prevalence does not matter. J. Clin. Epidemiol. 58:655-661. https://doi.org/ 10.1016/j.jclinepi.2004.02.021.

Vanbelle, S. 2016. A new interpretation of the weighted kappa coefficients. Psychometrika 81:399-410. https://doi.org/10.1007/s11336 -014-9439-4.

Whay, H. 2002. Locomotion scoring and lameness detection in dairy cattle. In Pract. 24:444-449. https://doi.org/10.1136/inpract.24.8 .444 .

Whay, H. R., A. E. Waterman, A. J. F. Webster, and J. K. O'Brien. 1998. The influence of lesion type on the duration of hyperalgesia associated with hindlimb lameness in dairy cattle. Vet. J. 156:2329. https://doi.org/10.1016/S1090-0233(98)80058-0.

Wickham, H. 2009. ggplot2: Elegant Graphics for Data Analysis. Springer-Verlag, New York, NY.

Wickham, H., R. Francois, L. Henry, and K. Müller. 2017. dplyr: A grammar of data manipulation. $\mathrm{R}$ package version 0.7.4. https:// CRAN.R-project.org $/$ package $=$ dplyr.

Wickham, H., and L. Henry. 2018. tidyr: Easily tidy data with "spread()" and "gather()" functions. R package version 0.8.0. https://CRAN.R-project.org/package=tidyr.

\section{ORCIDS}

Ruan R. Daros @ https://orcid.org/0000-0003-2331-1648

Marina A. G. von Keyserlingk () https://orcid.org/0000-0002-1427 $-3152$

Daniel M. Weary () https://orcid.org/0000-0002-0917-3982 


\section{APPENDIX}

In this appendix, we present complementary material related to the evaluation of inter-observer reliability measures for locomotion assessment. During training of the 2 observers who assessed locomotion, we used recorded videos and live scoring. We evaluated observer reliability after each step in the training, and after completing data collection. Tables A1 and A2 illustrate

Table A1. Inter-observer agreement for gait scoring from video (ordinal scale 1 to 5 )

\begin{tabular}{lrrrrrr}
\hline & \multicolumn{5}{c}{ Observer 1} \\
\cline { 2 - 5 } & 1 & 2 & 3 & 4 & 5 & \multirow{2}{*}{ Total } \\
\hline Observer 2 & 0 & 0 & 0 & 0 & 0 & 0 \\
1 & 1 & 9 & 1 & 0 & 0 & 11 \\
2 & 0 & 1 & 4 & 0 & 0 & 5 \\
3 & 0 & 0 & 1 & 3 & 0 & 4 \\
4 & 0 & 0 & 0 & 0 & 0 & 0 \\
5 & 1 & 10 & 6 & 3 & 0 & 20 \\
Total & & & & & & \\
\hline
\end{tabular}

Table A2. Inter-observer agreement for lameness categorization (sound or lame) from video

\begin{tabular}{lccc}
\hline & \multicolumn{2}{c}{ Observer 1} & \\
\cline { 2 - 3 } & Sound & Lame & Total \\
\hline Observer 2 & 10 & 1 & 11 \\
Sound & 1 & 8 & 9 \\
Lame & 11 & 9 & 20 \\
Total & & & \\
\hline
\end{tabular}

Table A3. Inter-observer agreement for pre-study live gait scoring (ordinal scale 1 to 5 )

\begin{tabular}{lrrrrrr}
\hline \multicolumn{5}{c}{ Observer 1} \\
\cline { 2 - 5 } & 1 & 2 & 3 & 4 & 5 & Total \\
\hline Observer 2 & 0 & 0 & 0 & 0 & 0 & 0 \\
1 & 0 & 20 & 3 & 0 & 0 & 23 \\
2 & 0 & 7 & 9 & 0 & 0 & 16 \\
3 & 0 & 0 & 0 & 1 & 0 & 1 \\
4 & 0 & 0 & 0 & 0 & 0 & 0 \\
5 & 0 & 27 & 12 & 1 & 0 & 40 \\
Total & & & & & & \\
\hline
\end{tabular}

interobserver agreement for the ordinal scale and classification of animals as sound or clinically lame from video. Tables A3 and A4 summarize the data from the pre-study evaluation of live locomotion assessment, and Tables A5 and A6 present the data from the reassessment of observer reliability after study completion. We used data in Tables A2, A4, and A6 when calculating prevalence and bias indices.

Table A4. Inter-observer agreement for pre-study live lameness categorization (sound or lame)

\begin{tabular}{lrrr}
\hline & \multicolumn{2}{c}{ Observer 1} & \\
\cline { 2 - 3 } & Sound & Lame & Total \\
\hline Observer 2 & 20 & & \\
Sound & 7 & 10 & 23 \\
Lame & 27 & 13 & 17 \\
Total & & & 40 \\
\hline
\end{tabular}

Table A5. Inter-observer agreement for live gait scoring after study completion (ordinal scale 1 to 5 )

\begin{tabular}{lrrrrrr}
\hline & \multicolumn{5}{c}{ Observer 1} \\
\cline { 2 - 5 } & 1 & 2 & 3 & 4 & 5 & \multirow{2}{*}{ Total } \\
\hline Observer 2 & 0 & 0 & 0 & 0 & 0 & 0 \\
1 & 0 & 17 & 5 & 0 & 0 & 22 \\
2 & 0 & 5 & 9 & 0 & 0 & 14 \\
3 & 0 & 0 & 0 & 1 & 0 & 1 \\
4 & 0 & 0 & 0 & 0 & 0 & 0 \\
5 & 0 & 22 & 14 & 1 & 0 & 37 \\
\hline
\end{tabular}

Table A6. Inter-observer agreement for live lameness categorization after study completion (sound or lame)

\begin{tabular}{lrrl}
\hline & \multicolumn{2}{c}{ Observer 1} & \\
\cline { 2 - 3 } & Sound & Lame & Total \\
\hline Observer 2 & 17 & 5 & \\
Sound & 5 & 10 & 22 \\
Lame & 22 & 15 & 15 \\
Total & & 37 \\
\hline
\end{tabular}

